\section{Measurement of tear production in Tawny owls (Strix aluco)}

\section{David Williams, Louise Cubbage}

Department of Veterinary Medicine, University of Cambridge, Cambridge, UK

Tawny owls (Strix aluco) are commonly presented to rehabilitation centres in the UK. In order to be released they must be in full ocular health. Many injured birds have ocular lesions and assessing tear production forms an important part of ophthalmic examination. Strigiformes, the owl family, are unusual in having small lacrimal glands and low tear production so that assessment of tear production using the standard Schirmer tear test (STT) is difficult. Here we evaluate both the STT and phenol red thread test (PRTT) in a group of Tawny owls.

Tear production was assessed using the STT and PRTT in twenty Tawny owls from a raptor rehabilitation centre, ten adult birds and ten juveniles. A full ophthalmic examination was undertaken in each bird. The PRTT was used first and ten minutes later the STT was performed, since the PRTT takes up less tear fluid than does the STT, this important in an eye with lo tear production.

The mean value \pm standard deviation (SD) for the PRTT in all eyes was $19.4 \pm 5.8 \mathrm{~mm} / 15$ seconds (range, 8 to $30 \mathrm{~mm} / 15 \mathrm{~s}$ ). The mean PRTT reading for juveniles was $14.8 \pm 1.9 \mathrm{~mm} / 15 \mathrm{~s}$ whereas the adult mean value was $21.5 \pm 5.9 \mathrm{~mm} / 15 \mathrm{~s}$, these significantly different at $p=0.016$. The mean \pm SD for the STT in all eyes was $5.6 \pm 3.3 \mathrm{~mm} / 60 \mathrm{~s}$ (range, $2-13 \mathrm{~mm} / 60 \mathrm{~s}$ ). The mean STT reading for juveniles was $3.2 \pm 1.5 \mathrm{~mm} / 60 \mathrm{~s}$ whereas the adult mean value was $6.7 \pm 3.4 \mathrm{~mm} / 60 \mathrm{~s}$, these significant different at $p=0.025$. The mean STT value OD was $5.2 \pm 2.6$ $\mathrm{mm} / 60 \mathrm{~s}$ (range, 3 to $10 \mathrm{~mm} / 60 \mathrm{~s}$ ). No correlation was found between the two tests in this study.

This study provides normal ranges for both tests ( 2 to 13 $\mathrm{mm} / 60 \mathrm{~s}$ and 8 to $30 \mathrm{~mm} / 15 \mathrm{~s}$, respectively) and mean values ( $5.6 \pm 3.3 \mathrm{~mm} / 60 \mathrm{~s}$ and $19.3 \pm 5.8 \mathrm{~mm} / 15 \mathrm{~s}$, respectively). The findings in this study reflect what has been shown of the two tests in other species, that there is a lack of correlation between them, probably because the PRTT measures tear lake volume while the STT defines tear lake volume and de novo tear production. For animals with small eyes and/or low tear production the PRTT may provide a more easily achieved and accurate measure of tear film dynamics than the STT.

\section{Assessing differences in approaches to ophthalmological cases between general practitioners and those with a special interest in ophthalmology}

\section{Marnie Brennan', Rachel Dean', Gareth Jones ${ }^{2}$, Corinne Wigfall', Sarah Baker', Martin Downes ${ }^{1}$}

\section{University of Nottingham, Leicestershire, UK}

The Park Vet Group, Leicestershire, UK

There is little peer-reviewed research published comparing the most effective way of treating important ophthalmological conditions which are commonly seen in small animal practice, such as keratoconjunctivitis sicca (KCS). Information on how veterinary general practitioners (GPS) or those with a special interest in ophthalmology currently treat ophthalmological conditions in veterinary patients is unknown. Establishing current practice would add to the existing knowledge base, but also identify areas of priority for research in veterinary ophthalmology.

The aim of this study was to investigate the current management and treatment of important ophthalmological conditions, focusing mainly on KCS, in small animal practice by GPS and those with a special interest in ophthalmology. Additionally, the resources that were used by both groups were examined.
A cross sectional survey was administered to GPs on a mailing list for the Centre for Evidence-based Veterinary Medicine (CEVM) and attendees at the British Association of Veterinary Ophthalmologists (BrAVO) winter congress 2011 \& 2012. Participants were asked about what treatment methods they used and where information was sourced about ophthalmic cases.

Both the majority of GPs and the special interest group nominated that they used topical cyclosporine as their drug of choice for the treatment of KCS $(92.2 \%$ and $98.7 \%$ respectively). Sixty three percent of GP respondents nominated using topical antibiotics compared to $41.6 \%$ of the specialist interest group. More of the specialist group stated they used topical (53.5\% versus $30.1 \%$ ) and carbomer lubricants $(53.2 \%$ versus $41.6 \%)$ than the GP group.

Both the special interest group and GPs ranked textbooks and then another specialist as their top two sources of information. The special interest group were more likely to nominate using a journal article for information whereas GPs were more likely to nominate CPD courses.

Differences were seen between the GP and special interest groups both in the nominated treatment approaches to $\mathrm{KCS}$, and in relation to some of the sources of information used for cases. This is possibly due to a general lack of published information, conflicting information about modes of therapy and effectiveness of drug treatments or differing clinical presentations. A more complete and reliable evidence base for managing ophthalmological conditions would develop and assist both practitioners and special interest groups in their clinical decision-making. 